\title{
Time evolution of groundwater quality in Dehui City
}

\author{
Hongyang Wei ${ }^{1,2, *}$, and Xiujuan Liang ${ }^{1,2}$ \\ ${ }^{1}$ Key Laboratory of Groundwater Resources and Environment, Ministry of Education, Jilin University, \\ Changchun 130021, China \\ ${ }^{2}$ College of New Energy and Environment, Jilin University, Changchun 130021, China
}

\begin{abstract}
The unreasonable development and utilization of groundwater in Dehui City, China, has resulted in poor groundwater quality conditions. Based on the collection of a large amount of groundwater chemical data and hydrogeological data collected by Dehui City from 1992 to 2015, this paper uses hydrogeological analysis, graphic and other methods and ArcGIS toolbox to analyze the groundwater quality of this City. The study shows that the concentration of groundwater chemical components in the vicinity of the Songhua River is decreasing with time, and the concentration of groundwater chemical components in other regions is increasing with time. The increase of chemical concentrations are affected by human activities and water-rock interaction. The decrease of groundwater chemical concentration in Songhua River area is caused by the mixing between dilute river water and groundwater.
\end{abstract}

\section{Introduction}

The evolution of groundwater quality has always been an important process in hydrogeological engineering ${ }^{[1]}$. Before industrial development, people studied the evolution of groundwater quality with the spatial and temporal evolution of groundwater chemistry under natural factors. More recently, the impact of human activities on groundwater has gradually increased. Research in this area has also attracted attention from the public as in this case of Dehui City. Dehui City, Jilin Province ( Fig. 1) is located in the central and northern part of Jilin Province and the central part of the Songliao Plain. The geographical span is between $44^{\circ} 02^{\prime}$ and $44^{\circ} 53^{\prime}$ north latitude and between $125^{\circ} 14^{\prime}$ and $126^{\circ} 24^{\prime}$ east longitude. Dehui City is located in a temperate continental monsoon climate zone. The average annual precipitation is $547 \mathrm{~mm}$, the average annual runoff depth is 55.2 $\mathrm{mm}$, the average annual water surface evaporation is $861 \mathrm{~mm}$, and the average evaporation of $20 \mathrm{~cm}$ caliber evaporating dish is $1350 \mathrm{~mm}$ [2].

Dehui City, is located on the southern edge of the Tianshan-Xing'anling trough fold area. The strata include the Middle to Upper part of the Jurassic, the Lower-Central part of the Cretaceous, and the Quaternary Periods. According to the division of aquifer rocks groundwater can be divided into two categories: loose-rock pore water and Cretaceous clastic rock pore fissure water [3].

*Corresponding author : $\underline{1104288005 @ q q . c o m}$ 


\section{Results and Discussions}

Through the statistical analysis of the existing data, the anion $\mathrm{HCO}_{3}{ }^{-}$predominates in the groundwater of the study area, and the highest content is $\sim 67 \%$, followed by $\mathrm{Cl}^{-} . \mathrm{Ca}^{2+}$ is the dominant cation, and the highest content is $69 \%$, followed by $\mathrm{Mg}^{2+}$. The $\mathrm{pH}$ value is between 6.8 and 7.5, and the salinity is $0.19-2.3 \mathrm{~g} / \mathrm{L}$, which belongs to low-mineralized fresh water. The total hardness is $110 \sim 1018 \mathrm{mg} / \mathrm{L}$. The Shukalev classification method was used to classify more than 200 water samples obtained from dozens of wells in Dehui City in 2009, 2012 and 2015. The water chemical types mainly include $\mathrm{HCO}_{3}{ }^{-} \mathrm{Ca}$ and $\mathrm{HCO}_{3}{ }^{-} \cdot \mathrm{Cl}-\mathrm{Ca} \cdot \mathrm{Mg}, \mathrm{HCO}_{3} \cdot \mathrm{Cl}-\mathrm{Ca}$ type water. The elevation of Dehui City is high in the south and low in the north. The groundwater runoff and discharge follow topography. After the groundwater passes through the Water-rock interaction, the chemical elements of the aqueous medium are dissolved and carried, and the excretion can be quickly taken away. Therefore, the city's groundwater salinity is generally not high.

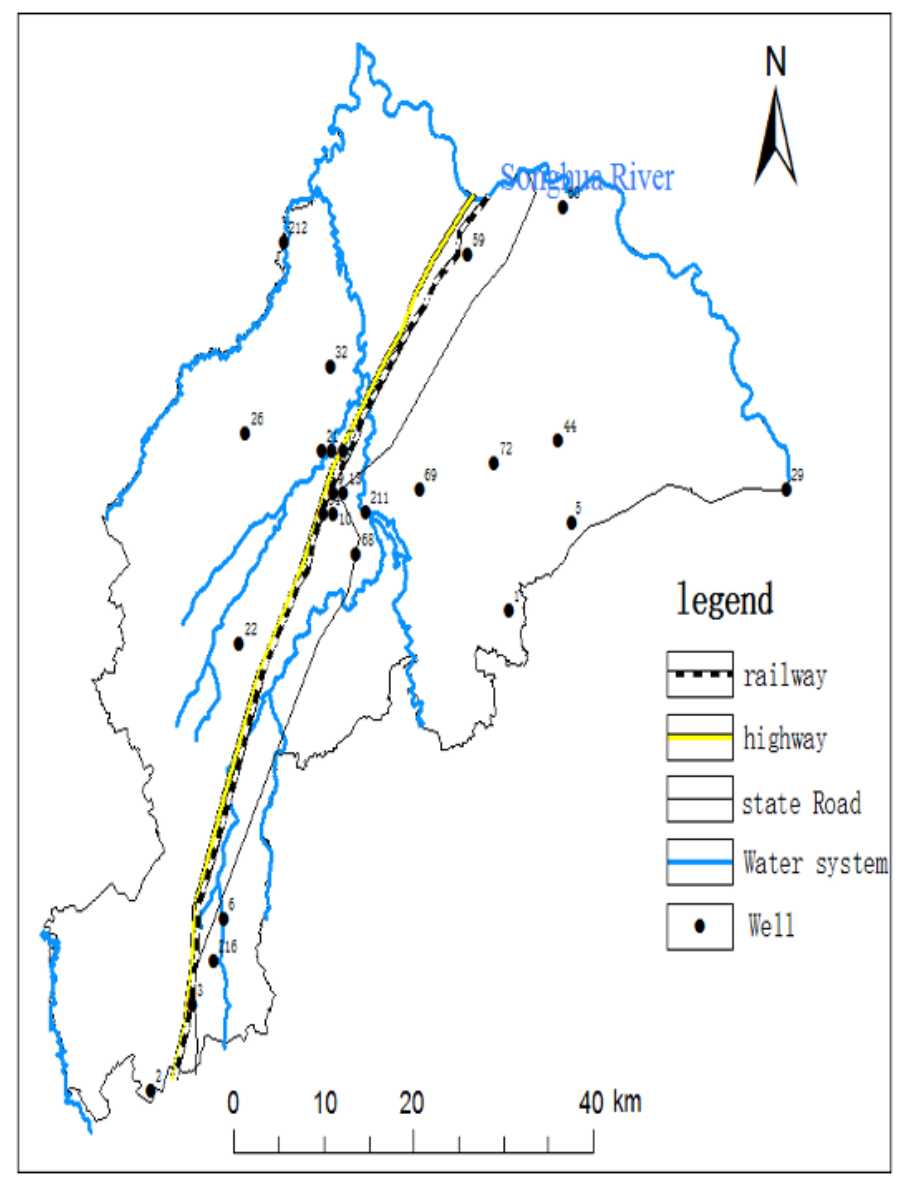

Fig.1. Map of the study area showing the well locations. 
The time evolution analysis of groundwater quality data from 1992 to 2010 in the study area was carried out, and the variation of each ion component with time was plotted as shown in Fig. 2 and Fig. 3. It can be seen that the ionic components in the groundwater of the Songhua River area tend to decline as a whole, and the ionic components in the groundwater in the plain area tend to rise as a whole.In fig 2 , the cation in equilibrium with $\mathrm{HCO}_{3}$-in 2006 was $\mathrm{H}^{+}$.

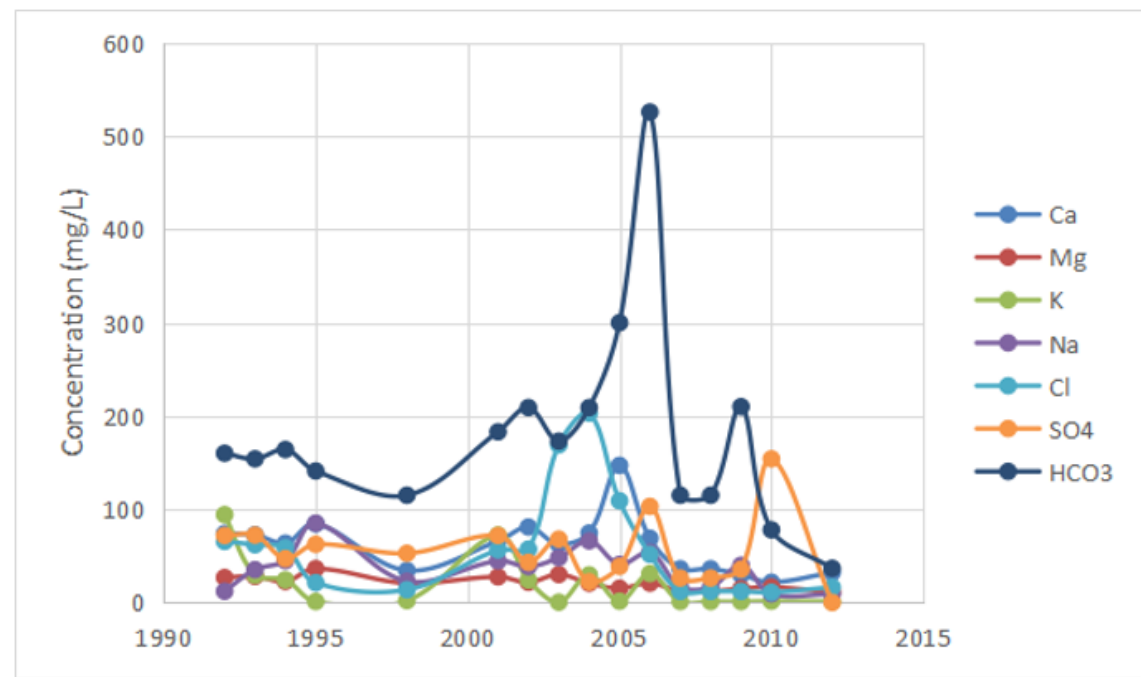

Fig. 2. Evolution of various ionic components of groundwater in Songhuajiang area over time.

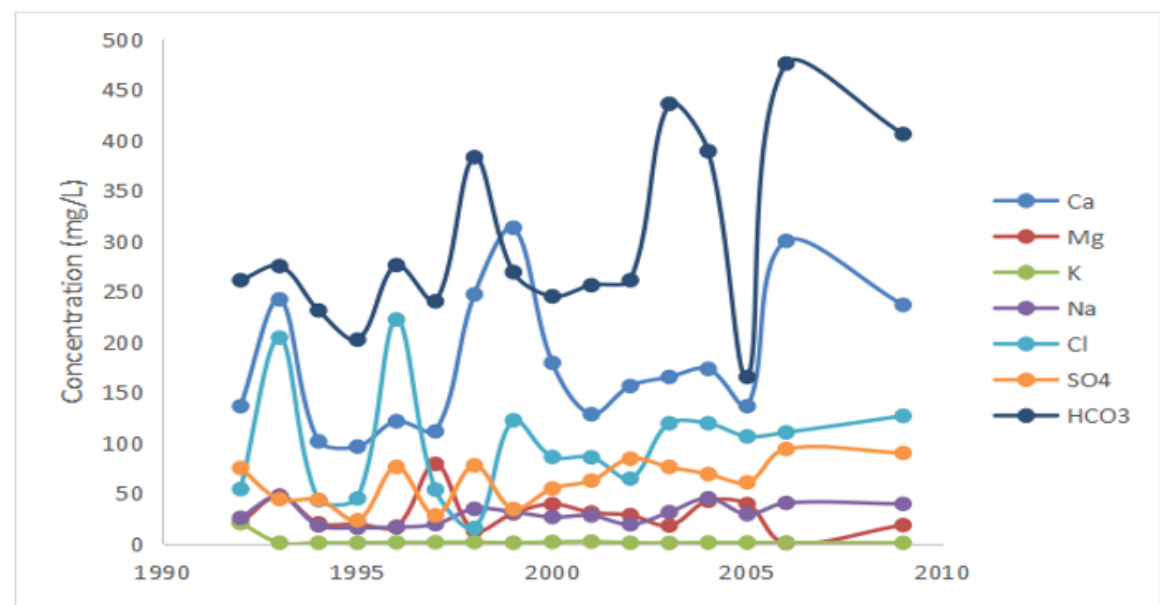

Fig. 3. Evolution of various ionic components in groundwater in the plain area over time.

The reason for this situation is presumed to be two phenomena: the increase in the content of various ionic components in groundwater caused by human activities, and the flushing effect of surface water.

\section{Conclusions}

Through this study, it can be concluded that the evolution of various ion components in groundwater in Dehui City follows different laws in different regions, and the difference is due to the close relationship between surface water and groundwater in different regions, 
and the closely related regions. Surface water will carry high concentrations of ions in the groundwater downstream, causing the concentration to decrease. Conversely, due to water-rock interaction, the ion concentration will increase.

\section{References}

1. M. Chen, J. Geological Science, 06:185-192, (1959)

2. Dehui City Water Resources Survey Report [R] .2007-2015

3. Changchun City National Economic Bulletin [R]. Changchun Municipal Bureau of Statistics. 2007-2015 